Pacific Journal of Mathematics

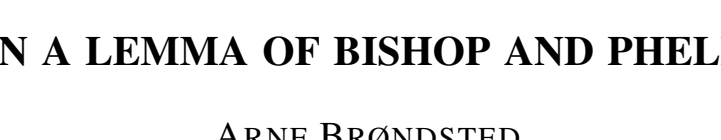




\title{
ON A LEMMA OF BISHOP AND PHELPS
}

\author{
ARne Brøndsted
}

The main purpose of the present note is to establish a theorem on the existence of maximal elements in certain partially ordered uniform spaces. The theorem unifies a lemma of E. Bishop and R. R. Phelps and a number of known extensions of this lemma.

1. In the proof of the fundamental theorem of E. Bishop and R. R. Phelps [1, Theorem 1] on the density of the set of support points of a closed convex subset of a Banach space, a lemma [1, Lemma 1] on the existence of maximal elements in certain partially ordered complete subsets of a normed linear space played a central role. Subsequently, this lemma was extended for various other purposes. Since none of the extensions is sufficiently general to cover all of them, it seems natural to look for a common generalization. In $\S 2$ we shall present such a general theorem. Actually, we first prove a theorem (Theorem 1) which is too general to be directly applicable, at least in the present context, and next we apply it to obtain the desired theorem (Theorem 2). The theorems are formulated in terms of uniform structures, due to the facts that completeness is the crucial assumption and that both nonmetric topological linear spaces and metric nonlinear spaces are to be covered. The proofs are heavily influenced by known arguments. In $\S 3$ we shall discuss the relations of Theorem 2 to the BishopPhelps lemma and its extensions. Finally, in $\S 4$ we shall give a simplified proof of a recent result of J. Daneš by applying the BishopPhelps procedure.

2. Everywhere in the following $E$ is assumed to be a nonempty set. By an extended real valued function on $E$ we shall mean a mapping $\varphi: E \rightarrow]-\infty,+\infty$, not identically $+\infty$. The set of points $x \in E$ such that $\varphi(x)<+\infty$ is denoted dom $\varphi$. When $E$ is equipped with a uniformity $\mathscr{C}$, and $\varphi$ is an extended real valued function on $E$, we shall say that $\varphi$ is inf-complete when the set of points $x \in E$ such that $\varphi(x) \leqq r$ is complete for each real $r$. Note that this implies lower semi-continuity of $\varphi$, and that the converse holds if $\mathscr{U}$ is a complete uniformity. By an ordering on $E$ we shall mean a reflexive, asymmetric and transitive relation $\leqq$; the corresponding irreflexive relation is denoted $\prec$. For $x \in E$ we shall denote by $S(x, \leqq)$ the set of points $y \in E$ such that $x \leqq y$. We shall say that an extended real valued function $\varphi$ on $E$ is decreasing resp. 
strictly decreasing (with respect to $\leqq$ ), if $x_{1} \prec x_{2}$ implies $\varphi\left(x_{1}\right) \geqq$ $\varphi\left(x_{2}\right)$ resp. $\varphi\left(x_{1}\right)>\varphi\left(x_{2}\right)$.

All uniformities and topologies considered are assumed to be Hausdorff. All linear spaces considered are assumed to be real.

THEOREM 1. Let $\mathscr{Q}$ be a uniformity on $E$, let $\leqq$ be an ordering on $E$, and let $\varphi$ be an extended real valued function on $E$ which is bounded below. Assume that the following conditions are fulfilled:

(a) The set $S(x, \leqq)$ is complete for each $x \in E$.

(b) The function $\varphi$ is decreasing.

(c) For each $U \in \mathscr{Q}$ there exists $\delta>0$ such that $x_{1} \leqq x_{2}$ and $\varphi\left(x_{1}\right)-\varphi\left(x_{2}\right)<\delta$ implies $\left(x_{1}, x_{2}\right) \in U$.

Then for each $x \in \operatorname{dom} \varphi$ there exists $x_{0} \in \operatorname{dom} \varphi$ such that $x \leqq x_{0}$ and $x_{0}$ is maximal in $(E, \leqq)$.

Proof. For any given point $x \in \operatorname{dom} \varphi$ there exists by Zorn's lemma a maximal totally ordered subset $M$ of $E$ containing $x$. We shall index the points of $M$ by the elements of a totally ordered set ( $I, \leqq)$ so that for $\alpha, \beta \in I$ we have $x_{\alpha} \leqq x_{\beta}$ if and only if $\alpha \leqq \beta$. Since $\varphi$ is bounded below and decreasing, the net $\left(\varphi\left(x_{\alpha}\right)\right)_{\alpha \in I}$ converges to some $a \in]-\infty,+\infty[$. Let $U \in \mathscr{U}$ be given, and let $\delta>0$ be such that (c) is fulfilled. Choose $\alpha \in I$ such that $\varphi\left(x_{\alpha}\right)<a+\delta$. Then for $\alpha<\beta \prec \gamma$ we have $\left(x_{\beta}, x_{\gamma}\right) \in U$ by (c). This shows that the net $\left(x_{\alpha}\right)_{\alpha \in I}$ is a Cauchy net, and hence, by (a), it converges to a point $x_{0}$ with $x_{\alpha} \leqq x_{0}$ for all $\alpha \in I$. In particular, $x \leqq x_{0}$. By the nature of $M$ it next follows that $x_{0}$ is maximal in $(E, \leqq)$. Finally, (b) implies $x_{0} \in \operatorname{dom} \varphi$.

REMARK 1. As is well known, the use of Zorn's lemma may be replaced by an induction argument (involving the axiom of choice) along the following lines. Let $x_{1}=x$, let $E_{1}=S\left(x_{1}, \leqq\right)$ and let $a_{1}=\inf \varphi\left(E_{1}\right)$. When $x_{1}, x_{2}, \cdots, x_{n}$ have been chosen, let $E_{n}=S\left(x_{n}, \leqq\right)$, let $a_{n}=\inf \varphi\left(E_{n}\right)$, and choose $x_{n+1} \in E_{n}$ such that $\varphi\left(x_{n+1}\right) \leqq a_{n}+n^{-1}$. In doing so, one obtains sequences $\left(x_{n}\right)_{n \in N}$ and $\left(a_{n}\right)_{n \in N}$ such that $x_{n} \leqq$ $x_{n+1}, a_{n} \leqq a_{n+1} \leqq \varphi(x), a_{n} \leqq \varphi\left(x_{n+1}\right) \leqq a_{n}+n^{-1}$. Using these relations and the idea of the proof above, the conclusion follows.

REMARK 2. We add an obvious but useful remark. Let $E, \mathscr{U}$, $\varphi$, and $\leqq$ be as assumed in Theorem 1 , and let $\leqq$ be an ordering on $E$ which is finer than $\leqq$, i.e., $x_{1} \leqq x_{2}$ implies $x_{1} \leqq x_{2}$. Then $(b)$ and (c) are also fulfilled for $\varliminf^{\prime}$. Therefore, if (a) is fulfilled for 
$\varliminf^{\prime}$, then the theorem applies to $\varliminf^{\prime}$. Even if (a) does not hold for $\leqq$, we may still conclude, however, that there exists $x_{0} \in \operatorname{dom} \varphi$ which is maximal in $\left(E, \varliminf^{\prime}\right)$, due to the fact that if $x_{0}$ is maximal with respect to $\leqq$, then it is also maximal with respect to $\leqq$ '.

In order to obtain the desired theorem, we shall apply Theorem 1 to certain orderings which we shall denote $\varliminf_{d, \varphi}$. Let $E$ be a set, and let $d$ be a nonnegative extended real valued function on $E \times E$ satisfying the following conditions:

(d) $d(x, y)=0$ if and only if $x=y$.

(e) $d(x, z) \leqq d(x, y)+d(y, z)$.

Furthermore, let $\phi$ be an extended real valued function on $E$. We then define $\leqq_{d, \varphi}$ as follows: $x_{1} \leqq_{d, \varphi} x_{2}$ if and only if either $x_{1}=x_{2}$, or $x_{1}, x_{2} \in \operatorname{dom} \varphi$ and $d\left(x_{1}, x_{2}\right) \leqq \varphi\left(x_{1}\right)-\varphi\left(x_{2}\right)$. Then it is easily checked that $\leqq_{d, \varphi}$ is in fact an ordering and that $\varphi$ is strictly decreasing with respect to $\leqq_{d, \varphi}$, cf. (b). Also, if $E$ is equipped with a uniformity such that $\phi$ is inf-complete and the functions $y \rightarrow d(x, y), x \in E$, are lower semi-continuous, then for each $x \in E$ the set $S\left(x, \varliminf_{d, \varphi}\right)$ is a closed subset of a complete set, and hence complete, cf. (a). Finally, note that if for each $U \in \mathscr{Q}$ there exists $\delta>0$ such that $d(x, y)<\delta$ implies $(x, y) \in U$, then (c) holds for $\varliminf_{d, \varphi}$. Therefore, by Theorem 1 we have:

THEOREM 2. Let $\mathscr{Q}$ be a uniformity on $E$, let $d$ be a nonnegative extended real valued function on $E \times E$ satisfying (d) and (e), and let $\varphi$ be an extended real valued function on $E$ which is bounded below. Assume that the following conditions are fulfilled:

(f) The function $\varphi$ is inf-complete.

(g) The functions $y \rightarrow d(x, y), x \in E$, are lower semi-continuous.

(h) For each $U \in \mathscr{Q}$ there exists $\delta>0$ such that $d(x, y)<\delta$ implies $(x, y) \in U$.

Then for each $x \in \operatorname{dom} \varphi$ there exists $x_{0} \in \operatorname{dom} \varphi$ such that $x \leqq_{d, \varphi} x_{0}$ and $x_{0}$ is maximal in $\left(E\right.$, $\left.\leqq_{d, \varphi}\right)$, i.e.,

$$
\varphi\left(x_{0}\right) \leqq \varphi(x)-d\left(x, x_{0}\right),
$$

and

$$
\varphi(y)>\varphi\left(x_{0}\right)-d\left(x_{0}, y\right)
$$

for all $y \in E \backslash\left\{x_{0}\right\}$.

REMARK 3. Note that if $\varliminf^{\prime}$ is finer than $\varliminf_{d, \varphi}$, then under the conditions of Theorem 2 there exists $x_{0}$ which is maximal in $\left(E, \leqq^{\prime}\right)$, and if in addition the sets $S\left(x, \leqq^{\prime}\right)$ are closed, then we may obtain $x \leqq x_{0}$ for any given $x$; cf. Remark 2 . 
3. In this section we shall clarify the relations of Theorem 2 to the Bishop-Phelps lemma and the most general extensions known to the author, namely that of I. Ekeland [5, Théorème 1] for complete metric spaces, and that of $R$. R. Phelps [6, Lemma 1] for non-metric topological linear spaces.

Note first that if $d$ is a metric on $E$, then the conditions (d) and (e) are fulfilled. Furthermore, if one takes $\mathscr{U}$ to be the uniformity on $E$ generated by $d$, then $(\mathrm{g})$ and $(\mathrm{h})$ hold. Hence, if $E$ is a metric space with metric $d$, and $\varphi$ is bounded below and inf-complete on $E$ (in particular, if $d$ is a complete metric, and $\varphi$ is bounded below and lower semi-continuous), then Theorem 2 applies. Adding the obvious remark that $\varphi$ may be replaced by $k^{-1} \varphi$ for any $k>0$, one obtains (under the condition stated) for each $x \in \operatorname{dom} \varphi$ an $x_{0} \in \operatorname{dom} \varphi$ such that

$$
\varphi\left(x_{0}\right) \leqq \varphi(x)-k d\left(x, x_{0}\right)
$$

and

$$
\varphi(y)>\varphi\left(x_{0}\right)-k d\left(x_{0}, y\right)
$$

for all $y \in E \backslash\left\{x_{0}\right\}$. This statement is essentially the theorem of I. Ekeland.

To obtain the result of $\mathrm{R}$. R. Phelps, let $X$ be a topological linear space, and let $C$ be a closed, bounded, convex subset of $X$ containing $o$. Let $\mu$ be the gauge function of $C$, i.e.,

$$
\mu(x)=\inf \{\lambda>0 \mid x \in \lambda C\}
$$

for $x \in X$, and let $d(x, y)=\mu(x-y)$ for $x, y \in X$. Then, as is well known, $d$ maps $X \times X$ into $[0,+\infty]$ (with $d(x, y)=+\infty$ if and only if $C$ does not absorb $x-y$ ), and the conditions (d) and (e) are fulfilled. Also, if $\mathscr{C}$ is taken to be the uniformity given on $X$ ( $X$ being a topological linear space), then $(\mathrm{g})$ and $(\mathrm{h})$ hold; for $(\mathrm{g})$, the closedness of $C$ is essential, for $(h)$, the boundedness is essential. Therefore, if $E$ is a subset of $X$, and $\varphi$ is bounded below and infcomplete on $E$ (in particular, if $E$ is complete and $\varphi$ is bounded below and lower semi-continuous) then Theorem 2 applies. Noting, as before, that $\varphi$ may replaced by $k^{-1} \varphi$ for any $k>0$, one obtains a slight reformulation of the result of $R$. $R$. Phelps, stating that (under the conditions above) for each $x \in \operatorname{dom} \varphi$ there exists $x_{0} \in$ $\operatorname{dom} \varphi$ such that

$$
\varphi(x) \leqq \varphi(x)-k \mu\left(x-x_{0}\right),
$$

and

$$
\varphi(y)>\varphi\left(x_{0}\right)-k_{\mu} \mu\left(x_{0}-y\right)
$$


for all $y \in E \backslash\left\{x_{0}\right\}$. (In [6], the set corresponding to the set $C$ above is not assumed to be convex. This condition seems necessary, however, to ensure that the relation considered be an ordering. For all the applications in [6], the appropriate set is in fact convex.)

Note that if one takes $d(x, y)=\|x-y\|=\mu(x-y)$, both of the two cases above covers the case of $E$ being a subset of a normed linear space. In particular, both cases covers the original lemma of Bishop and Phelps which we shall briefly review. Let $E$ be a complete subset of a normed linear space $X$, let $\xi$ be a nonzero continuous linear functional on $X$ which is bounded above on $E$, and let $k>0$. Then the set

$$
K(\xi, k)=\{x \in X \mid\|x\| \leqq k\langle x, \xi\rangle\}
$$

is a closed convex cone in $X$. (Note that $K(\xi, k)=\{0\}$ when $k\|\xi\|<$ 1, and that int $K(\xi, k) \neq \varnothing$ when $k\|\xi\|>1$.) Being also proper, the cone determines an ordering $\leqq$ on $X$ in the usual manner, and the ordering on $E$ induced by $\leqq$ is simply $\varliminf_{d, \varphi}$ with $d(x, y)=$ $\|x-y\|$ and $\varphi(x)=-k\langle x, \xi\rangle$. Therefore, for each $x \in E$ there exists $x_{0} \in E$ such that $x \leqq x_{0}$ and $x_{0}$ is maximal in $(E, \leqq)$. This is the lemma of Bishop and Phelps, slightly reformulated. In this connection, note that if $\varliminf^{\prime}$ is an ordering on $X$ determined by a convex subcone $C$ of $K(\xi, k)$, then by Remark 3 we may still conclude the existence of a point $x_{0} \in E$ such that $x_{0}$ is maximal in $(E, \leqq ')$; and if in addition $C$ is closed, we may obtain $x \leqq^{\prime} x_{0}$ for a given $x \in E$. This covers a result of F. E. Browder [2, Lemma 2].

For a review of applications of the Bishop-Phelps procedure in the case of orderings on Banach spaces generated by convex cones, see R. R. Phelps [8]. In particular, this paper contains a comprehensive bibliography. For applications in more general cases, see e.g. A. Brøndsted and R. T. Rockafellar [3], R. R. Phelps [7] and the papers of Ekeland and Phelps quoted above. See also $\S 4$.

4. By a drop $D(z, r, y)$ in a normed linear space $X$ we shall mean the convex hull of a closed ball $B(z, r)$ and a point $y$ not belonging to the ball. This notion was introduced by J. Daneš who proved the following [4, Drop Theorem]:

THEOREM 3 (J. Daneš). Let $F$ be a closed subset of a Banach space $X$, and let $z$ be a point in $X \backslash F$. Let $0<r<R<\rho$, where $R=\operatorname{dist}(z, F)$. Then there exists a point $x_{0} \in b d F$ such that $\left\|x_{0}-z\right\| \leqq \rho$ and $D\left(z, r, x_{0}\right) \cap F=\left\{x_{0}\right\}$.

This theorem is related to a theorem of F. E. Browder [2, Theorem 4]. Roughly speaking, Browder proves that a certain drop 
may be translated to "support" the appropriate set, i.e., the "peak" is the only point of the drop that belongs to the set, whereas Daneš proves that for certain given $z$ and $r$ there exists a "supporting" drop of the particular form $D(z, r, y)$ for a suitable $y$. The proof of Browder's theorem depends on the lemma of Browder referred to in $\S 3$; hence the Bishop-Phelps procedure applies with an ordering defined by a convex cone. Although not explicitly stated, the proof of J. Daneš also contains a sort of a Bishop-Phelps argument. We shall give a considerably clarified version of the proof by applying directly the Bishop-Phelps procedure (with an ordering not generated by a convex cone).

Proof (Theorem 3). Without loss of generality we may assume that $z=o$. We define a relation $\leqq$ on the set $E=F \cap B(o, \rho)$ by putting $x_{1} \leqq x_{2}$ if and only if $x_{2} \in D\left(o, r, x_{1}\right)$. It is easily checked that $\leqq$ is in fact an ordering. Let

$$
\varphi(x)=\frac{\rho+r}{R-r}\|x\|
$$

for $x \in E$. It is claimed that $\leqq$ is finer than the ordering $\varliminf_{d, \varphi}$, where $d(x, y)=\|x-y\|$. Let $x_{1}$ and $x_{2}$ be points in $E$ such that $x_{1} \prec x_{2}$. From the definition of a drop it then follows that

$$
x_{2}=(1-t) x_{1}+t v
$$

for appropriate $t \in] 0,1\left[\right.$ and $v \in B(o, r)$. By (1), we have $\left\|x_{2}\right\| \leqq$ $(1-t)\left\|x_{1}\right\|+t\|v\|$, whence

$$
t\left(\left\|x_{1}\right\|-\|v\|\right) \leqq\left\|x_{1}\right\|-\left\|x_{2}\right\| \text {. }
$$

On the other hand, we clearly have $R-r \leqq\left\|x_{1}\right\|-\|v\|$, and we therefore obtain

$$
t \leqq\left(\left\|x_{1}\right\|-\left\|x_{2}\right\|\right)(R-r)^{-1} .
$$

From (1) it also follows that $x_{2}-x_{1}=t\left(v-x_{1}\right)$. Using this and (2) we get

$$
\begin{aligned}
\left\|x_{2}-x_{1}\right\| & =t\left\|v-x_{1}\right\| \leqq t\left(\|v\|+\left\|x_{1}\right\|\right) \\
& \leqq t(r+\rho) \leqq(\rho+r)(R-r)^{-1}\left(\left\|x_{1}\right\|-\left\|x_{2}\right\|\right),
\end{aligned}
$$

as desired. Now, by Theorem 2 (see also $\S 3$ ), there exists a maximal element $x_{0}$ in $\left(E, \varliminf_{d, \varphi}\right)$. But then $x_{0}$ is also maximal in $(E, \leqq)$, cf. Remark 3. This proves that $\left\|x_{0}\right\| \leqq \rho$ and that $x_{0}$ is the only point of $D\left(o, r, x_{0}\right)$ belonging to $E$. But then $x_{0}$ is the only point of $D\left(o, r, x_{0}\right)$ belonging to the given set $F$, since the points in $D\left(o, r, x_{0}\right)$ 
have norm $\leqq \rho$, whereas the points in $F \backslash E$ have norm $>\rho$. Finally, it is obvious that $x_{0}$ is a boundary point of $F$.

Note that since a drop is closed, we may obtain $x_{0} \in D(z, r, x)$ for any given $x \in F$ with $\|x-z\| \leqq \rho$, cf. Remark 3 .

\section{REFERENCES}

1. E. Bishop and R. R. Phelps, The support functionals of a convex set, Proc. Symp. Pure Math. VII, Convexity, Amer. Math. Soc., (1963), 27-36.

2. F. E. Browder, Normal solvability and the Fredholm alternative for mappings into infinite dimensional manifolds, J. Funct. Anal., 8 (1971), 250-274.

3. A. Brøndsted and R. T. Rockafellar, On the subdifferentiability of convex functions, Proc. Amer. Math. Soc., 16 (1965), 605-611.

4. J. Daneš, A geometric theorem useful in nonlinear functional analysis, Bollettino U.M.I. (4), 6 (1972), 369-375.

5. I. Ekeland, Sur les problèmes variationelles, C. R. Acad. Sci. Paris Sér. A, 275 (1972), 1057-1059.

6. R. R. Phelps, Support cones and their generalizations, Proc. Symp. Pure Math. VII, Convexity, Amer. Math. Soc., (1963), 393-401.

7. - Weak* support points of convex sets in $E^{*}$, Israel J. Math., 2 (1964), $177-182$.

8. - Support cones in Banach spaces and their applications, Advances in Math., 13 (1974), 1-19.

Received March 23, 1973.

UNIVERSITY OF COPENHAGEN

DENMARK 



\section{PACIFIC JOURNAL OF MATHEMATICS}

\section{EDITORS}

RICHARD ARENS (Managing Editor)

University of California

Los Angeles, California 90024

\section{R. A. Beaumont \\ University of Washington \\ Seattle, Washington 98105}

\section{J. DugundJI}

Department of Mathematics

University of Southern California

Los Angeles, California 90007

D. Gilbarg and J. Milgram

Stanford University

Stanford, California 94305

\section{ASSOCIATE EDITORS}
E. F. BECKENBACH
B. H. NeumanN
F. WOLF
K. YOSHIDA

\section{SUPPORTING INSTITUTIONS}

UNIVERSITY OF BRITISH COLUMBIA
CALIFORNIA INSTITUTE OF TECHNOLOGY
UNIVERSITY OF CALIFORNIA
MONTANA STATE UNIVERSITY
UNIVERSITY OF NEVADA
NEW MEXICO STATE UNIVERSITY
OREGON STATE UNIVERSITY
UNIVERSITY OF OREGON
OSAKA UNIVERSITY

UNIVERSITY OF BRITISH COLUMBIA

UNIVERSITY OF CALIFORNIA

MONTANA STATE UNIVERSITY

NEW MEXICO STATE UNIVERSITY

OREGON STATE UNIVERSITY

OSAKA UNIVERSITY

\author{
UNIVERSITY OF SOUTHERN CALIFORNIA \\ STANFORD UNIVERSITY \\ UNIVERSITY OF TOKYO \\ UNIVERSITY OF UTAH \\ WASHINGTON STATE UNIVERSITY \\ UNIVERSITY OF WASHINGTON \\ AMERICAN MATHEMATICAL SOCIETY \\ NAVAL WEAPONS CENTER
}

The Supporting Institutions listed above contribute to the cost of publication of this Journal, but they are not owners or publishers and have no responsibility for its content or policies.

Mathematical papers intended for publication in the Pacific Journal of Mathematics should be in typed form or offset-reproduced, (not dittoed), double spaced with large margins. Underline Greek letters in red, German in green, and script in blue. The first paragraph or two must be capable of being used separately as a synopsis of the entire paper. Items of the bibliography should not be cited there unless absolutely necessary, in which case they must be identified by author and Journal, rather than by item number. Manuscripts, in triplicate, may be sent to any one of the editors. Please classify according to the scheme of Math. Reviews, Index to Vol. 39. All other communications should be addressed to the managing editor, or Elaine Barth, University of California, Los Angeles, California, 90024.

The Pacific Journal of Mathematics expects the author's institution to pay page charges, and reserves the right to delay publication for nonpayment of charges in case of financial emergency.

100 reprints are provided free for each article, only if page charges have been substantially paid. Additional copies may be obtained at cost in multiples of 50 .

The Pacific Journal of Mathematics is issued monthly as of January 1966. Regular subscription rate: $\$ 72.00$ a year (6 Vols., 12 issues). Special rate: $\$ 36.00$ a year to individual members of supporting institutions.

Subscriptions, orders for back numbers, and changes of address should be sent to Pacific Journal of Mathematics, 103 Highland Boulevard, Berkeley, California, 94708.

PUBLISHED BY PACIFIC JOURNAL OF MATHEMATICS, A NON-PROFIT CORPORATION

Printed at Kokusai Bunken Insatsusha (International Academic Printing Co., Ltd.), 270, 3-chome Totsuka-cho, Shinjuku-ku, Tokyo 160, Japan.

Copyright (C) 1973 by Pacific Journal of Mathematics Manufactured and first issued in Japan 


\section{Pacific Journal of Mathematics \\ Vol. 55, No. $2 \quad$ October, 1974}

Walter Allegretto, On the equivalence of two types of oscillation for elliptic

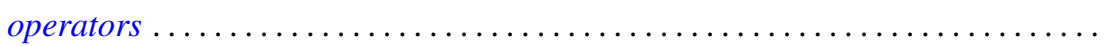

Edward Arthur Bertram, A density theorem on the number of conjugacy classes in

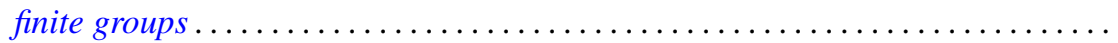

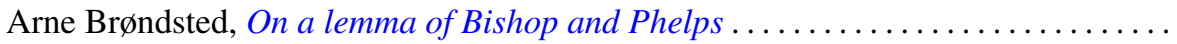

Jacob Burbea, Total positivity and reproducing kernels ..................

Ed Dubinsky, Linear Pincherle sequences . . . . . . . . . . . . . . . . . .

Benny Dan Evans, Cyclic amalgamations of residually finite groups .............

361

Barry J. Gardner and Patrick Noble Stewart, A "going down" theorem for certain

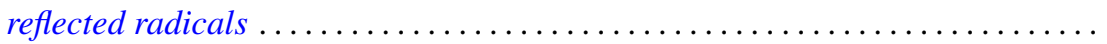

381

Jonathan Light Gross and Thomas William Tucker, Quotients of complete graphs:

revisiting the Heawood map-coloring problem ....................

Sav Roman Harasymiv, Groups of matrices acting on distribution spaces .........

Robert Winship Heath and David John Lutzer, Dugundji extension theorems for

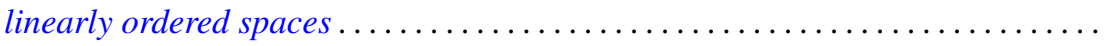

Chung-Wu Ho, Deforming p. l. homeomorphisms on a convex polygonal

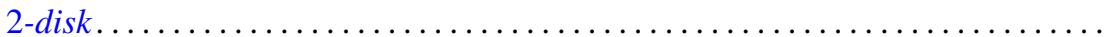

Richard Earl Hodel, Metrizability of topological spaces .................

Wilfried Imrich and Mark E. Watkins, On graphical regular representations of

cyclic extensions of groups .......................... 461

Jozef Krasinkiewicz, Remark on mappings not raising dimension of curves ..... . 479

Melven Robert Krom, Infinite games and special Baire space extensions . . . . . . 483

S. Leela, Stability of measure differential equations . . . . . . . . . . . . . . . . 489

M. H. Lim, Linear transformations on symmetric spaces . . . . . . . . . . . . . . . 499

Teng-Sun Liu, Arnoud C. M. van Rooij and Ju-Kwei Wang, On some group algebra modules related to Wiener's algebra $M_{1} \ldots \ldots \ldots \ldots \ldots \ldots \ldots \ldots \ldots \ldots \ldots$

Dale Wayne Myers, The back-and-forth isomorphism construction ............ 521

Donovan Harold Van Osdol, Extensions of sheaves of commutative algebras by

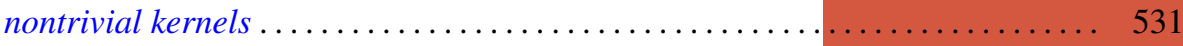

Alan Rahilly, Generalized Hall planes of even order ................... 543

Joylyn Newberry Reed, On completeness and semicompleteness of first countable

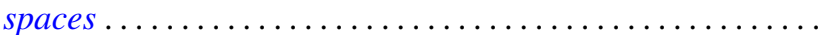

Alan Schwartz, Generalized convolutions and positive definite functions associated

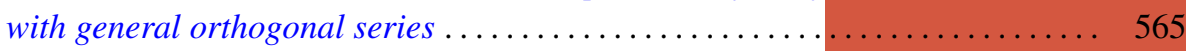

Thomas Jerome Scott, Monotonic permutations of chains . . . . . . . . . . . 583

Eivind Stensholt, An application of Steinberg's construction of twisted groups .... 595

Yasuji Takeuchi, On strongly radicial extensions . . . . ................. 619

William P. Ziemer, Some remarks on harmonic measure in space . . . . . . . . . . 629

John Grant, Corrections to: “Automorphisms definable by formulas” . . . . . . . . 639

Peter Michael Rosenthal, Corrections to: "On an inversion for the general

Mehler-Fock transform pair" ......................... 640

Carl Clifton Faith, Corrections to: "When are proper cyclics injective” . . . . . . 640 